\title{
Implementasi Keamanan Data Gaji Karyawan Pada PT. Capella Medan Menggunakan Metode Advanced Encryption Standard (AES)
}

Jaka Prayudha, Saniman, Ishak

* Program Studi Sistem Informasi, STMIK Triguna Dharma

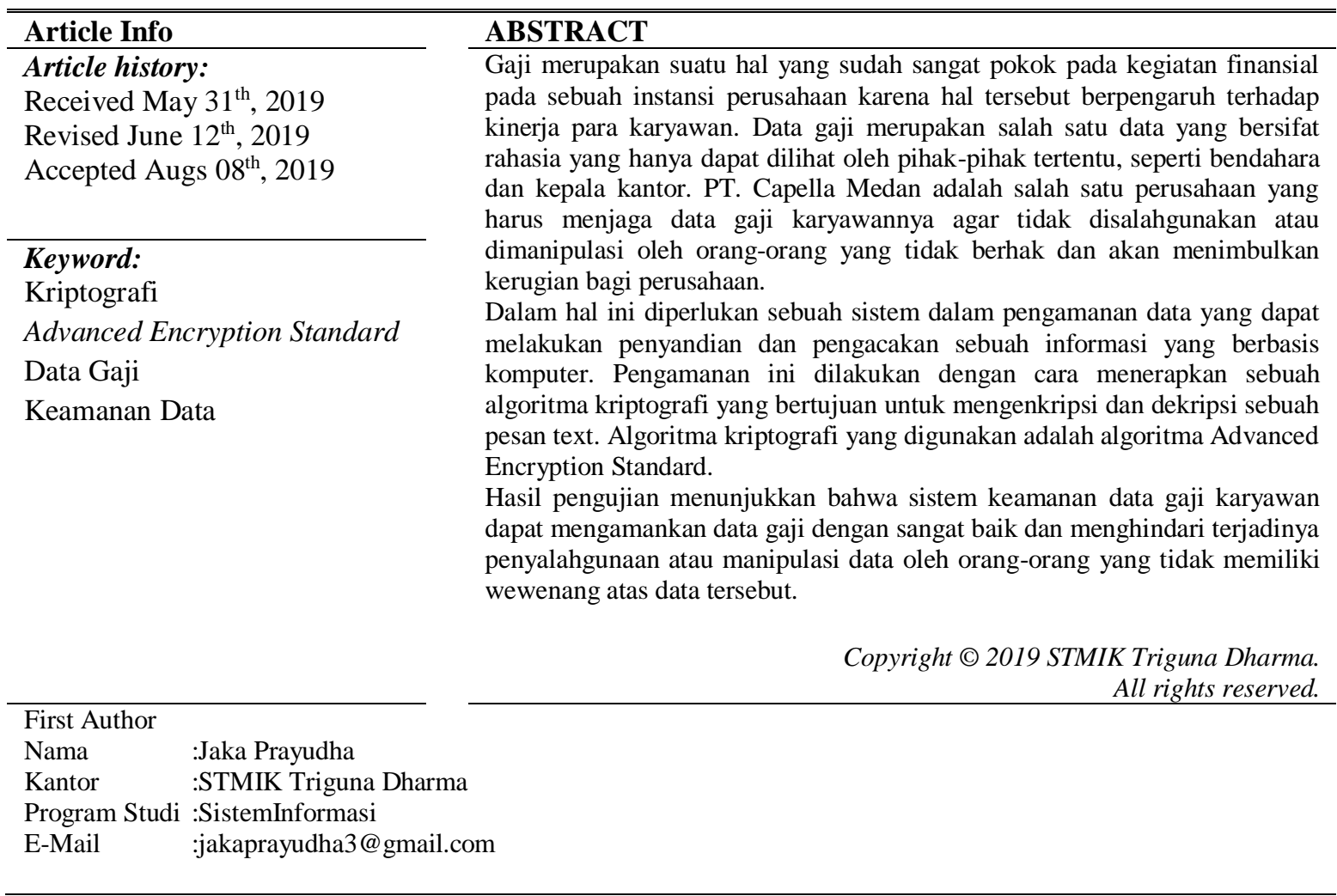

\section{PENDAHULUAN}

PT. Capella Medan adalah salah satu perusahaan swasta yang bergerak dibidang otomotif di wilayah Sumatera Utara. Dalam PT. Capella Medan, gaji yang diterima karyawan sesuai UMR setiap bulannya, dan pemberian bonus diadakan tiap tahunnya sesuai disiplin dan semangat kerja karyawan, staff, dan mekanik. Data gaji karyawan merupakan salah satu data rahasia yang hanya dapat dikelola oleh bendahara atau kepala kantor. Oleh karena itu, pihak perusahaan berusaha untuk mengamankan data tersebut agar terhindar dari penyalahgunaan atau manipulasi data oleh orang-orang yang tidak berhak yang dapat mengakibatkan kerugian pada perusahaan.

Data gaji pada perusahaan ini yaitu file text dari Microsoft Excel, isi file ini akan di input pada aplikasi yang akan digunakan, akan rawan terjadinya penyalahgunaan dan manipulasi data yang akan menyebabkan kerugian bagi pihak perusahaan.

Dalam hal ini dibutuhkan sistem keamanan untuk mengamankan data gaji karyawan PT. Capella Medan. Keamanan pada sistem ini menggunakan ilmu kriptografi modern yang menggunakan penyandian dalam sistemnya, dan metode yang digunakan adalah metode Advanced Encryption Standard.

Proses dalam pengamanan data gaji karyawan ini yaitu dengan melakukan enkripsi dengan merubah data text atau pesan (plaintext) menjadi data sandi (plaintext), dan dekripsi adalah merubah data sandi (plaintext) menjadi data text atau pesan (ciphertext). 


\section{METODE PENELITIAN}

2.1 Gaji

Menurut Mulyadi (dalam Utami, 2014) 'gaji dapat didefinisikan secara global sebagai pembayaran atas penyerahan jasa yang dibayarkan kepada karyawan yang memiliki jenjang jabatan manajer dan pada umumnya merupakan pembayaran atas penyerahan jasa yang dilakukan oleh karyawan pelaksana (bagian produksi) dan dibayarkan berdasarkan pada hari kerja, jam kerja, atau jumlah satuan produk yang telah dihasilkan oleh karyawan'.

\subsection{Kriptografi}

Kriptografi berasal dari bahasa Yunani, menurut bahasa dibagi menjadi dua kripto dan graphia, kripto berarti secret (rahasia) dan graphia berarti writing (tulisan). Menurut terminologinya, kriptografi adalah ilmu dan seni untuk menjaga keamanan pesan ketika pesan dikirim dari suatu tempat ketempat yang lain (Ariyus, 2018 : 9). Kata "seni" tersebut berasal dari fakta sejarah bahwa pada masa-masa awal sejarah kriptografi setiap orang mungkin mempunyai cara yang unik untuk merahasiakan pesannya.

Pengamanan pada data dilakukan untuk menjaga kerahasiaan informasi dan agar aman dari orang-orang yang tidak bertanggung jawab, maka dilakukanlah pengamanan data dengan menggunakan algortima kriptografi.

\subsection{Advanced Encryption Standard}

Advanced Encryption Standard merupakan algoritma kriptografi simetrik yang beroperasi dalam mode penyandian blok (block cipher) yang memproses blok data 128-bit dengan panjang kunci 128-bit, 192-bit, dan 256-bit. Beberapa mode operasi yang dapat diterapkan pada algoritma kriptografi penyandi blok AES di antaranya adalah Electronic Code Book (ECB), Cipher Block Chaining (CBC), Cipher Feedback (CFB), dan Output Feedback (OFB). Implementasi AES dengan mode operasi ECB, CBC, CFB, dan OFB tentu saja memiliki kelebihan dan kekurangan tertentu dalam aspek tingkat keamanan data. Algoritma kriptografi bernama Rijndael yang didesain oleh oleh Vincent Rijmen dan John Daemen asal Belgia keluar sebagai pemenang kontes

Algoritma kriptografi pengganti DES yang diadakan oleh NIST (National Institutes of Standards and Technology) milik pemerintah Amerika Serikat pada 26 November 2001. Algoritma Rijndael inilah yang kemudian dikenal dengan Advanced Encryption Standard (AES). Setelah mengalami beberapa proses standardisasi oleh NIST, Rijndael kemudian diadopsi menjadi standard algoritma kriptografi secara resmi pada 22 Mei 2002. Pada 2006, AES merupakan salah satu algoritma terpopuler yang digunakan dalam kriptografi kunci simetrik.

\subsubsection{Proses Ekspansi Kunci}

Proses Ekspansi Kunci Algoritma AES mengambil kunci cipher dan melakukan rutin ekspansi kunci untuk membentuk key schedule. Ekspansi kunci menghasilkan total $\mathrm{Nb}(\mathrm{Nr}+1)$ word. Algoritma ini membutuhkan set awal key yang terdiri dari $\mathrm{Nb}$ word, dan setiap round $\mathrm{Nr}$ membutuhkan data kunci sebanyak $\mathrm{Nb}$ word. Hasil key schedule terdiri dari array 4 byte word linear yang dinotasikan dengan [ wi ]. SubWord adalah fungsi yang mengambil 4 byte word input dan mengaplikasikan SBox ke tiap-tiap data 4 byte untuk menghasilkan word output. Fungsi RotWord mengambil word [a0, a1, a2, a3] sebagai input, melakukan permutasi siklik, dan mengembalikan word [a1, a2, a3, a0]. Rcon[i] terdiri dari nilai-nilai yang diberikan oleh $[\mathrm{xi}-1,\{00\},\{00\},\{00\}]$, dengan xi-1 sebagai pangkat dari x (x dinotasikan sebagai $\{02\}$ ).

\subsubsection{Proses Enkripsi}

Proses enkripsi adalah proses penyandian plaintext menjadi ciphertext, atau pengubahan data menjadi bentuk rahasia. Proses enkripsi algoritma AES terdiri dari 4 jenis transformasi bytes, yaitu SubBytes, ShiftRows, Mixcolumns, dan AddRoundKey. Pada awal proses enkripsi, input yang telah dicopykan ke dalam state akan mengalami transformasi byte AddRoundKey. Setelah itu, state akan mengalami transformasi SubBytes, ShiftRows, MixColumns, dan AddRoundKey secara berulang-ulang sebanyak Nr. Proses ini dalam algoritma AES disebut sebagai round function. Round yang terakhir agak berbeda dengan round-round sebelumnya dimana pada round terakhir, state tidak mengalami transformasi MixColumns. Ilustrasi proses enkripsi AES dapat digambarkan seperti pada Gambar di bawah ini : 


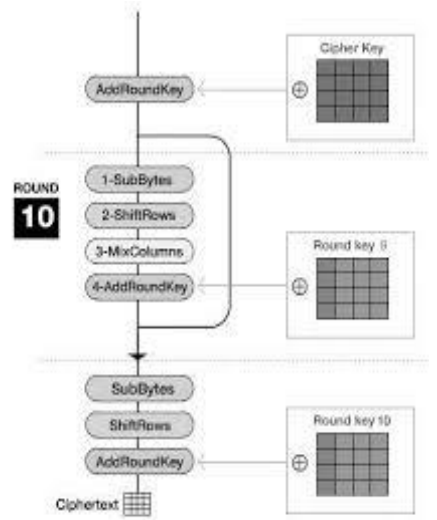

Gambar 1 Diagram enkripsi AES

Garis besar algoritma AES Rijndael yang beroperasi pada blok 128-bit dengan kunci 128bit (diluar proses pembangkitan roundkey) adalah sebagai berikut:

1. AddRoundKey, melakukan XOR antara awal (plaintext) dengan cipher key.

2. Putaran sebanyak Nr-1 kali. Proses yang dilakukan pada setiap putaran adalah :

a. SubBytes adalah subsitusi byte menggunakan tabel subsitusi (S-Box).

b. ShiftRows adalah pergeseran baris-baris array state secara wrapping.

c. Mix Columns adalah mengacak data di masing-masing kolom array state.

d. AddRoundKey adalah melakukan XOR antara state sekarang round key.

3. Final round, proses untuk putaran terakhir :

a. SubBytes

b. ShiftRows

c. AddRoundKey

Langkah kerja enkripsi adalah sebagai berikut:

a. Transformasi SubBytes

SubBytes merupakan transformasi byte dimana setiap elemen pada state akan dipetakan dengan menggunakan sebuah tabel substitusi ( S-Box ). Tabel substitusi S-Box akan dipaparkan dalam Gambar 2.

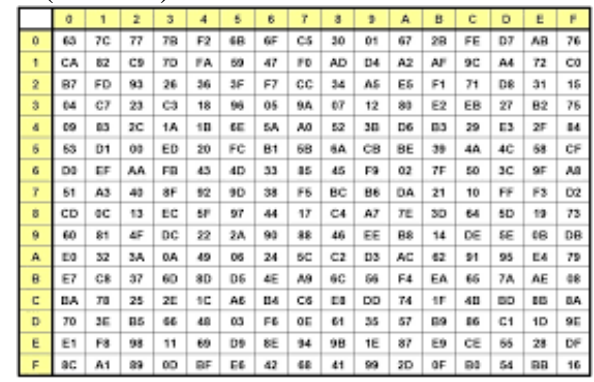

Gambar 2 S-Box Rijdael

Untuk setiap byte pada array state, misalkan $\mathrm{S}[\mathrm{r}, \mathrm{c}]=\mathrm{xy}$, yang dalam hal ini $\mathrm{xy}$ adalah digit heksadesimal dari nilai $\mathrm{S}[\mathrm{r}, \mathrm{c}]$, maka nilai substitusinya, dinyatakan dengan $\mathrm{S}$ ' $[\mathrm{r}, \mathrm{c}]$, adalah elemen di dalam tabel subtitusi yang merupakan perpotongan baris x dengan kolom y. Gambar 3 mengilustrasikan pengaruh pemetaan byte pada setiap byte dalam state.

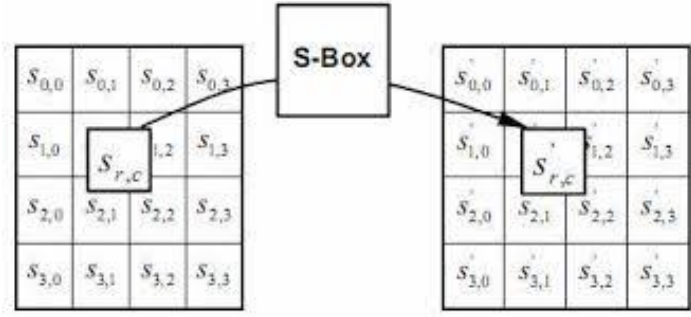

Gambar 3 Pengaruh pemetaan pada setiap Byte dalam state

\section{b. Shiftrows}

Transformasi Shiftrows pada dasarnya adalah proses pergeseran bit dimana bit paling kiri akan dipindahkan menjadi bit paling kanan (rotasi bit). Proses pergeseran Shiftrows ditunjukkan dalam Gambar 4 berikut: 


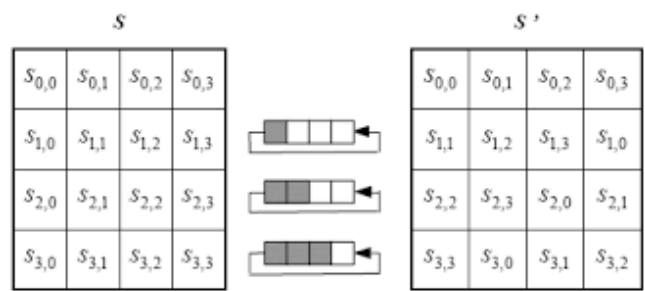

Gambar 4 Proses shifrows

\section{c. MixColumns}

MixColumns mengoperasikan setiap elemen yang berada dalam satu kolom pada state. Secara lebih jelas, transformasi mixcolumns dapat dilihat pada perkalian matriks berikut ini:

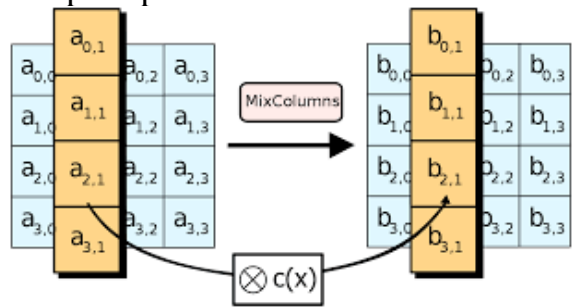

Gambar 5 Proses mixcolumns

d. AddRoundKey

AddRoundKey melakukan XOR antara state sekarang dengan round key.

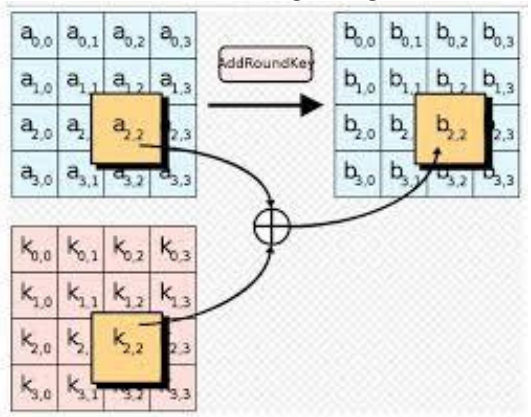

\subsubsection{Proses Dekripsi}

Gambar 6 Proses addroundKey

Transformasi cipher dapat dibalikkan dan diimplementasikan dalam arah yang berlawanan untuk menghasilkan inverse cipher yang mudah dipahami untuk algoritma AES. Transformasi byte yang digunakan pada invers cipher adalah InvShiftRows, InvSubBytes, InvMixColumns, dan AddRoundKey. Algoritma dekripsi dapat dilihat pada skema berikut ini :

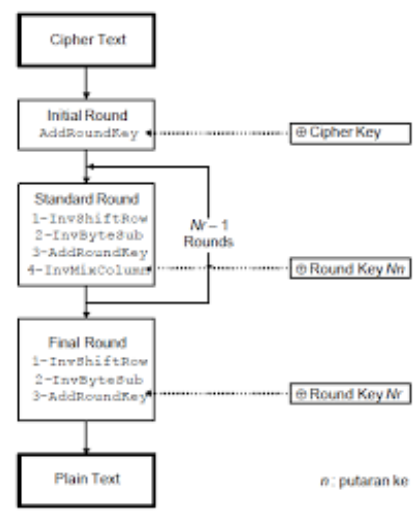

a. InvShiftRows

Gambar 7 Proses dekripsi

InvShiftRows adalah transformasi byte yang berkebalikan dengan transformasi ShiftRows. Pada transformasi InvShiftRows, dilakukan pergeseran bit ke kanan sedangkan pada ShiftRows dilakukan pergeseran bit ke kiri. Ilustrasi transformasi InvShiftRows terdapat pada Gambar 8: 


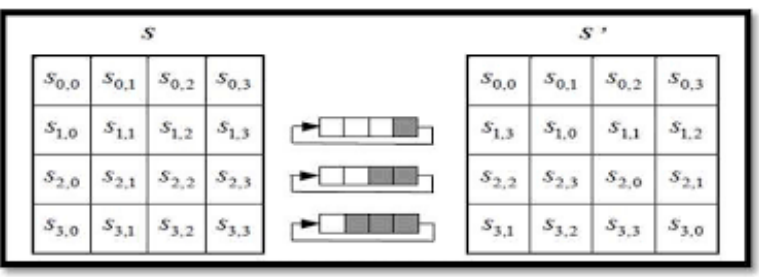

b. InvSubBytes

Gambar 8 Proses invshiftrows

InvSubBytes juga merupakan transformasi bytes yang berkebalikan dengan transformasi SubBytes. Pada InvSubBytes, tiap elemen pada state dipetakan dengan menggunakan tabel Inverse S-Box.

\section{c. InvMixColumns}

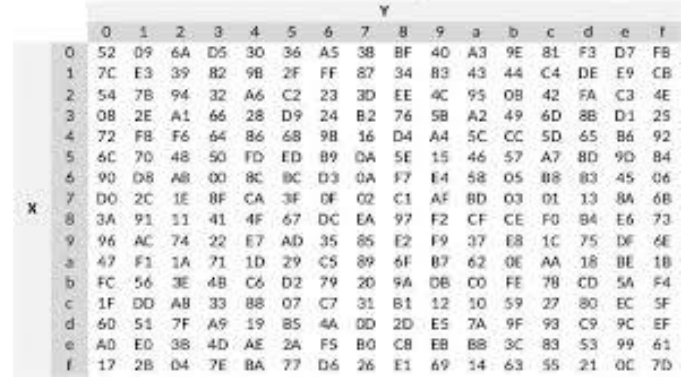

Gambar 9 Proses invsubbytes

Setiap kolom dalam state dikalikan dengan matrik perkalian dalam AES. Perkalian dalam matrik dapat dituliskan:

d. Inverse AddRoundKey

$$
\left[\begin{array}{l}
s_{0, c}^{\prime} \\
s_{1, c} \\
s_{2, c}^{\prime} \\
s_{3, c}^{\prime}
\end{array}\right]=\left[\begin{array}{llll}
0 E & 0 B & 0 D & 09 \\
09 & 0 E & 0 B & 0 D \\
0 D & 09 & 0 E & 0 B \\
0 B & 0 D & 09 & 0 E
\end{array}\right]\left[\begin{array}{l}
s_{0, c} \\
s_{1, c} \\
s_{2, c} \\
s_{3, c}
\end{array}\right]
$$

Transformasi Inverse AddRoundKey tidak berbeda dengan transformasi AddRoundkey karna dalam transformasi ini hanya dilakukan operasi penambahan sederhana dengan operasi bitwise XOR.

\section{ANALISA DAN HASIL}

\subsection{Algoritma Sistem}

Adapun algoritma dalam metode Advanced Encryption Standard yang akan digunakan untuk menyelesaikan permasalahan adalah melakukan proses ekspansi kunci, enkripsi, dan dekripsi.

\subsubsection{Proses Ekspansi Kunci}

Kunci ronde (round key) dibutuhkan untuk proses enkripsi dan dekripsi pada algoritma Advanced Encryption Standard. Maksimal panjang kunci adalah sebanyak 16 digit dan jumlah kunci ronde yang diperlukankan adalah 10 kunci yang akan diperoleh dari proses ekspansi kunci. Pada kasus ini, kunci yang akan digunakan yaitu "Novithalis Lubis".

1. Urutkan kunci kedalam blok berukuran 128 bit (16 kode ASCII). Lalu ubah kunci kedalam bentuk hexadecimal.

\begin{tabular}{|c|c|c|c|c|c|c|c|c|c|c|c|c|c|c|c|}
\hline $\mathrm{N}$ & $\mathrm{O}$ & $\mathrm{v}$ & $\mathrm{i}$ & $\mathrm{t}$ & $\mathrm{h}$ & $\mathrm{a}$ & $\mathrm{l}$ & $\mathrm{i}$ & $\mathrm{s}$ & & $\mathrm{L}$ & $\mathrm{u}$ & $\mathrm{b}$ & $\mathrm{i}$ & $\mathrm{s}$ \\
\hline $4 \mathrm{E}$ & $6 \mathrm{~F}$ & 76 & 69 & 74 & 68 & 61 & $6 \mathrm{C}$ & 69 & 73 & 20 & $4 \mathrm{C}$ & 75 & 62 & 69 & 73 \\
\hline
\end{tabular}

2. Langkah selanjutnya yaitu susun kunci yang telah diubah kedalam bentuk hexadecimal ke dalam state berukuran $4 \times 4$ seperti dibawah ini :

$\left.\begin{array}{|l|l|l|l|}\hline 4 \mathrm{E} & 74 & 69 & 75 \\ \hline 6 \mathrm{~F} & 68 & 73 & 62 \\ \hline 76 & 61 & 20 & 69 \\ \hline 69 & 6 \mathrm{C} & 4 \mathrm{C} & 73 \\ \hline\end{array}\right\}$ Cipherkey / kunci ronde ke - 0

3. Setelah itu, untuk mendapatkan hasil kolom pertama pada sub kunci, langkah pertama yaitu dilakukan fungsi RotWord yaitu dengan menggeser setiap bit pada kolom ke-4 ke atas 1 kali dari kunci ronde ke-0. 


\begin{tabular}{|l|l|}
\hline 62 \\
\hline 69 \\
\hline 73 \\
\hline
\end{tabular}$\longrightarrow$\begin{tabular}{|l|}
\hline 69 \\
\hline 73 \\
\hline 75 \\
\hline
\end{tabular}

4. Kemudian hasil dari RotWord disubtitusikan dengan nilai pada tabel S-Box (SubBytes).

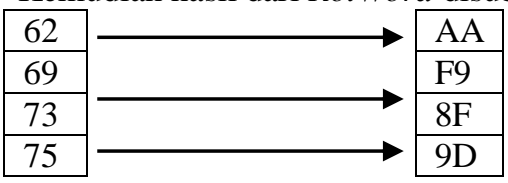

5. Tahap kolom pertama yaitu proses XOR antara kolom pertama dari kunci ronde ke-0 dan hasil dari SubBytes lalu di-XOR-kan lagi dengan RC.
\begin{tabular}{|l|}
\hline $4 \mathrm{E}$ \\
\hline $6 \mathrm{~F}$ \\
\hline 76 \\
\hline 69 \\
\hline
\end{tabular}

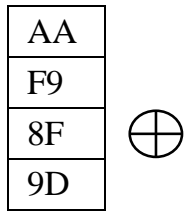
\begin{tabular}{|l|}
\hline 01 \\
\hline 00 \\
\hline 00 \\
\hline 00 \\
\hline
\end{tabular}$=$\begin{tabular}{|l|}
\hline $\mathrm{E} 5$ \\
\hline 96 \\
\hline $\mathrm{F} 9$ \\
\hline $\mathrm{F} 4$ \\
\hline
\end{tabular}
kolom pertama
(wi) pada kunci
$76 \bigoplus$
9D
ronde selanjutnya
$($ ronde ke-1) $=\mathrm{K} 1$

6. Untuk mendapatkan kolom kedua, diperoleh dengan XOR antara Wi dengan kolom kedua dari kunci ronde ke- 0 . Untuk mendapatkan kolom ketiga dan keempat kunci ronde ke-1, dilakukan proses seperti memperoleh kolom kedua.

\begin{tabular}{|c|c|c|c|c|}
\hline 74 & & E5 & & 91 \\
\hline 68 & & 96 & & $\mathrm{FE}$ \\
\hline 61 & $\oplus$ & F9 & $=1$ & 98 \\
\hline 6C & & F4 & & 98 \\
\hline
\end{tabular}

Kolom ke-2

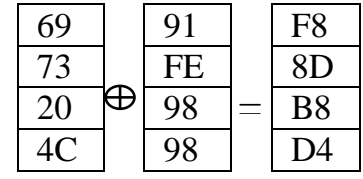

Kolom ke-3

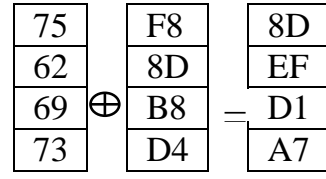

Kolom ke-4

7. Dari seluruh proses diatas, maka diperoleh kunci untuk ronde ke-1 yaitu :

\begin{tabular}{|l|l|l|l|}
\hline E5 & 91 & F8 & $8 D$ \\
\hline 96 & FE & $8 D$ & EF \\
\hline F9 & 98 & B8 & D1 \\
\hline F4 & 98 & D4 & A7 \\
\hline
\end{tabular}

Algoritma Advanced Encryption Standard 128 bit ini memiliki 10 ronde sehingga diperlukan 10 kunci ronde (round key). Untuk mendapatkan kunci ronde ke-2 sampai ke-10, proses diatas diulang sampai 10 kali. Kunci masing-masing ronde akan digunakan saat proses enkripsi dan dekripsi. Dibawah ini adalah hasil ekpansi kunci hingga ronde ke 10:

\subsubsection{Proses Enkripsi}

$\left[\begin{array}{llll}\text { E5 } & 91 & \text { F8 } & 8 D \\ 96 & \text { FE } & \text { 8D } & \text { EF } \\ \text { F9 } & 98 & \text { B8 } & \text { D1 } \\ \text { F4 } & 98 & \text { D4 } & \text { A7 }\end{array}\right]\left[\begin{array}{cccc}38 & \text { A9 } & 51 & \text { DC } \\ \text { A8 } & 56 & \text { D8 } & 34 \\ \text { A5 } & 3 \mathrm{D} & 85 & 54 \\ \text { A9 } & 31 & \text { E5 } & 42\end{array}\right] .\left[\begin{array}{cccc}1 \mathrm{E} & 6 C & \text { F5 } & \text { D3 } \\ 1 \mathrm{~F} & 89 & \text { AA } & 5 B \\ \text { BB } & 85 & 9 F & 80 \\ \text { B8 } & 41 & 2 A & 71\end{array}\right]$

Kunci Ronde Ke-1 Kunci Ronde Ke-2 $\quad \ldots \quad$ Kunci Ronde Ke-10

Plaintext yang akan digunakan yaitu "14750000". Urutkan kedalam blok dan ubah ke bilangan heksadesimal.

\begin{tabular}{|c|c|c|c|c|c|c|c|c|c|c|c|c|c|c|c|}
\hline 1 & 4 & 7 & 5 & 0 & 0 & 0 & 0 & & & & & & & & \\
\hline 31 & 34 & 37 & 35 & 30 & 30 & 30 & 30 & 20 & 20 & 20 & 20 & 20 & 20 & 20 & 20 \\
\hline
\end{tabular}

Kemudian susun 16 byte pertama dari plaintext yang telah diubah ke bentuk heksadesimal kedalam state $4 \times 4$ :

\begin{tabular}{|l|l|l|l|}
\hline 31 & 30 & 20 & 20 \\
\hline 34 & 30 & 20 & 20 \\
\hline 37 & 30 & 20 & 20 \\
\hline 35 & 30 & 20 & 20 \\
\hline
\end{tabular}

Lakukan XOR dengan kunci ronde ke-0. Proses ini dinamakan AddRoundKey.

\begin{tabular}{|l|l|l|l|}
\hline 31 & 30 & 20 & 20 \\
\hline 34 & 30 & 20 & 20 \\
\hline 37 & 30 & 20 & 20 \\
\hline 35 & 30 & 20 & 20 \\
\hline
\end{tabular}

\begin{tabular}{|l|l|l|l|}
\hline $4 \mathrm{E}$ & 74 & 69 & 75 \\
\hline $6 \mathrm{~F}$ & 68 & 73 & 62 \\
\hline 76 & 61 & 20 & 69 \\
\hline 69 & $6 \mathrm{C}$ & $4 \mathrm{C}$ & 73 \\
\hline
\end{tabular}

Proses diatas masih dalam pra-round. Hasil dari AddRoundKey diatas akan menjadi masukan untuk ronde ke1 yang akan diproses dengan 4 transformasi yaitu SubBytes, ShiftRows, MixColumns dan AddRoundKey. Round 1 


\begin{tabular}{|c|c|c|c|}
\hline \multicolumn{4}{|c|}{ Text } \\
\hline $7 \mathrm{~F}$ & 44 & 49 & 55 \\
\hline $5 \mathrm{~B}$ & 58 & 53 & 42 \\
\hline 41 & 51 & 00 & 49 \\
\hline $5 \mathrm{C}$ & $5 \mathrm{C}$ & $6 \mathrm{C}$ & 53 \\
\hline \multicolumn{4}{|c|}{ MixColumns } \\
\hline 45 & $0 \mathrm{C}$ & 01 & $4 \mathrm{E}$ \\
\hline $\mathrm{C} 2$ & $6 \mathrm{E}$ & $3 \mathrm{~B}$ & 05 \\
\hline 14 & $8 \mathrm{~A}$ & 92 & 58 \\
\hline E3 & $\mathrm{BB}$ & 30 & 83 \\
\hline
\end{tabular}

Text

\begin{tabular}{|c|c|c|c|}
\hline A0 & $9 \mathrm{D}$ & F9 & C3 \\
\hline 54 & 90 & B6 & EA \\
\hline ED & 12 & $2 A$ & 89 \\
\hline 17 & 23 & E4 & 24 \\
\hline
\end{tabular}

MixColumns

\begin{tabular}{|c|c|c|c|}
\hline A0 & $8 \mathrm{~B}$ & FA & $2 \mathrm{E}$ \\
\hline F7 & $1 \mathrm{C}$ & 80 & $9 \mathrm{~B}$ \\
\hline EC & 20 & 39 & 52 \\
\hline 0F & $9 \mathrm{E}$ & $\mathrm{C} 9$ & 27 \\
\hline
\end{tabular}

.....

Round 10

Text
\begin{tabular}{|c|c|c|c|}
\hline 29 & 08 & F 9 & $1 \mathrm{E}$ \\
\hline 57 & 24 & A3 & FB \\
\hline 64 & 18 & $2 \mathrm{D}$ & F 2 \\
\hline 93 & $4 \mathrm{E}$ & $0 \mathrm{~B}$ & B 7 \\
\hline
\end{tabular}

RoundKey 10

\begin{tabular}{|c|c|c|c|}
\hline 1E & $6 \mathrm{C}$ & F5 & D3 \\
\hline 1F & 89 & AA & $5 \mathrm{~B}$ \\
\hline BB & 85 & $9 \mathrm{~F}$ & 80 \\
\hline B8 & 41 & $2 \mathrm{~A}$ & 71 \\
\hline
\end{tabular}

SubBytes
\begin{tabular}{|c|c|c|c|}
\hline D 2 & $1 \mathrm{~B}$ & $3 \mathrm{~B}$ & $\mathrm{FC}$ \\
\hline 39 & $6 \mathrm{~A}$ & $\mathrm{ED}$ & $2 \mathrm{C}$ \\
\hline 83 & $\mathrm{D} 1$ & 63 & $3 \mathrm{~B}$ \\
\hline $4 \mathrm{~A}$ & $4 \mathrm{~A}$ & 50 & $\mathrm{ED}$ \\
\hline
\end{tabular}

RoundKey 1

\begin{tabular}{|c|c|c|c|}
\hline E5 & 91 & F8 & $8 D$ \\
\hline 96 & FE & 8D & EF \\
\hline F9 & 98 & B8 & D1 \\
\hline F4 & 98 & D4 & A7 \\
\hline
\end{tabular}

SubBytes

\begin{tabular}{|c|c|c|c|}
\hline E0 & $5 \mathrm{E}$ & 99 & $2 \mathrm{E}$ \\
\hline 20 & 60 & $4 \mathrm{E}$ & 87 \\
\hline 55 & C9 & E5 & A7 \\
\hline F0 & 26 & 69 & 36 \\
\hline
\end{tabular}

RoundKey 2

\begin{tabular}{|c|c|c|c|}
\hline 38 & A9 & 51 & DC \\
\hline A8 & 56 & D8 & 34 \\
\hline A5 & 3D & 85 & 54 \\
\hline A9 & 31 & E5 & 42 \\
\hline
\end{tabular}

ShiftRows

\begin{tabular}{|c|c|c|c|}
\hline D2 & $1 \mathrm{~B}$ & $3 \mathrm{~B}$ & $\mathrm{FC}$ \\
\hline 2C & 39 & $6 \mathrm{~A}$ & $\mathrm{ED}$ \\
\hline 63 & $3 \mathrm{~B}$ & 83 & $\mathrm{D} 1$ \\
\hline ED & $4 \mathrm{~A}$ & $4 \mathrm{~A}$ & 50 \\
\hline
\end{tabular}

AddRoundKey

\begin{tabular}{|c|c|c|c|}
\hline A0 & $9 \mathrm{D}$ & F9 & C3 \\
\hline 54 & 90 & B6 & EA \\
\hline ED & 12 & $2 \mathrm{~A}$ & 89 \\
\hline 17 & 23 & E4 & 24 \\
\hline
\end{tabular}

ShiftRows

\begin{tabular}{|c|c|c|c|}
\hline E0 & $5 \mathrm{E}$ & 99 & $2 \mathrm{E}$ \\
\hline 87 & 20 & 60 & $4 \mathrm{E}$ \\
\hline E5 & A7 & 55 & C9 \\
\hline 36 & F0 & 26 & 69 \\
\hline
\end{tabular}

AddRoundKey

\begin{tabular}{|c|c|c|c|}
\hline 98 & 22 & $\mathrm{AB}$ & $\mathrm{F} 2$ \\
\hline $5 \mathrm{~F}$ & $4 \mathrm{~A}$ & 58 & $\mathrm{AF}$ \\
\hline 49 & $1 \mathrm{D}$ & $\mathrm{BC}$ & 06 \\
\hline $\mathrm{A} 6$ & $\mathrm{AF}$ & $2 \mathrm{C}$ & 65 \\
\hline
\end{tabular}

SubBytes

\begin{tabular}{|c|c|c|c|}
\hline A5 & 30 & 99 & 72 \\
\hline $5 \mathrm{~B}$ & 36 & $0 \mathrm{~A}$ & $0 \mathrm{~F}$ \\
\hline 43 & AD & D8 & 89 \\
\hline DC & $2 \mathrm{~F}$ & 2B & A9 \\
\hline
\end{tabular}

ShiftRows

\begin{tabular}{|c|c|c|c|}
\hline A5 & 30 & 99 & 72 \\
\hline 0F & $5 \mathrm{~B}$ & 36 & 0A \\
\hline D8 & 89 & 43 & AD \\
\hline A9 & DC & 2F & 2B \\
\hline
\end{tabular}

CipherText

\begin{tabular}{|c|c|c|c|}
\hline BB & $5 \mathrm{C}$ & $6 \mathrm{C}$ & $\mathrm{A} 1$ \\
\hline 10 & $\mathrm{D} 2$ & $9 \mathrm{C}$ & 51 \\
\hline 63 & $0 \mathrm{C}$ & $\mathrm{DC}$ & $2 \mathrm{D}$ \\
\hline 11 & $9 \mathrm{D}$ & 05 & $5 \mathrm{~A}$ \\
\hline
\end{tabular}

Hasil dari proses AddRoundKey pada ronde ke-10 merupakan hasil akhir proses enkripsi yaitu: BB1063115CD20C9D6C9CDC05A1512D5A.

\subsubsection{Proses Dekripsi}

Proses-proses transformasi pada dekripsi dalam metode Advanced Encryption Standard yaitu InvSubBytes, InvShiftRows, InvMixColumns dan AddRoundKey. AddRoundKey merupakan transformasi yang bersifat self-invers. Kunci yang digunakan sama dengan yang digunakan pada proses enkripsi. Berikut adalah proses dekripsi dari hasil ciphertext yang telah diperoleh dari proses enkripsi sebelumnya.

\section{$\underline{\text { Round } 1}$}

Chipertext
\begin{tabular}{|c|c|c|c|}
\hline BB & $5 \mathrm{C}$ & $6 \mathrm{C}$ & $\mathrm{A} 1$ \\
\hline 10 & $\mathrm{D} 2$ & $9 \mathrm{C}$ & 51 \\
\hline 63 & $0 \mathrm{C}$ & $\mathrm{DC}$ & $2 \mathrm{D}$ \\
\hline 11 & $9 \mathrm{D}$ & 05 & $5 \mathrm{~A}$ \\
\hline
\end{tabular}

AddRoundKey

\begin{tabular}{|c|c|c|c|}
\hline A5 & 30 & 99 & 72 \\
\hline 0F & $5 \mathrm{~B}$ & 36 & $0 \mathrm{~A}$ \\
\hline D8 & 89 & 43 & AD \\
\hline A9 & DC & $2 \mathrm{~F}$ & $2 \mathrm{~B}$ \\
\hline
\end{tabular}

Round 2
Text

\begin{tabular}{|c|c|c|c|}
\hline BB & $5 \mathrm{C}$ & $6 \mathrm{C}$ & A1 \\
\hline 10 & D2 & $9 \mathrm{C}$ & 51 \\
\hline 63 & $0 \mathrm{C}$ & DC & $2 \mathrm{D}$ \\
\hline 11 & $9 \mathrm{D}$ & 05 & $5 \mathrm{~A}$ \\
\hline
\end{tabular}

InvShiftRows

\begin{tabular}{|c|c|c|c|}
\hline A5 & 30 & 99 & 72 \\
\hline $5 B$ & 36 & $0 A$ & $0 F$ \\
\hline 43 & AD & D8 & 89 \\
\hline DC & $2 \mathrm{~F}$ & $2 \mathrm{~B}$ & A9 \\
\hline
\end{tabular}

RoundKey 10

\begin{tabular}{|c|c|c|c|}
\hline $1 \mathrm{E}$ & $6 \mathrm{C}$ & $\mathrm{F} 5$ & $\mathrm{D} 3$ \\
\hline 1F & 89 & AA & $5 \mathrm{~B}$ \\
\hline BB & 85 & $9 \mathrm{~F}$ & 80 \\
\hline B8 & 41 & $2 \mathrm{~A}$ & 71 \\
\hline
\end{tabular}

\begin{tabular}{|l|l|l|l|}
\hline InvSubBytes \\
\hline 29 & 08 & F9 & $1 \mathrm{E}$ \\
\hline 57 & 24 & A3 & FB \\
\hline 64 & 18 & $2 \mathrm{D}$ & F2 \\
\hline 93 & $4 \mathrm{E}$ & 0B & B7 \\
\hline
\end{tabular}




Text
\begin{tabular}{|c|c|c|c|}
\hline 29 & 08 & F 9 & $1 \mathrm{E}$ \\
\hline 57 & 24 & A 3 & FB \\
\hline 64 & 18 & $2 \mathrm{D}$ & F 2 \\
\hline 93 & $4 \mathrm{E}$ & $0 \mathrm{~B}$ & B 7 \\
\hline
\end{tabular}

RoundKey 9
\begin{tabular}{|c|c|c|c|}
\hline 89 & 72 & 99 & 26 \\
\hline DF & 96 & 23 & F 1 \\
\hline 86 & $3 \mathrm{E}$ & $1 \mathrm{~A}$ & $1 \mathrm{~F}$ \\
\hline 47 & F9 & $6 \mathrm{~B}$ & $5 \mathrm{~B}$ \\
\hline
\end{tabular}

AddRoundKey
\begin{tabular}{|c|c|c|c|}
\hline A0 & $7 \mathrm{~A}$ & 60 & 38 \\
\hline 88 & B 2 & 80 & $0 A$ \\
\hline E 2 & 26 & 37 & ED \\
\hline D4 & B7 & 60 & EC \\
\hline
\end{tabular}

\section{InvMixColumns}

\begin{tabular}{|c|c|c|c|}
\hline 0D & $3 \mathrm{D}$ & 84 & 95 \\
\hline D9 & 32 & 20 & DA \\
\hline 73 & D3 & A6 & 26 \\
\hline B9 & 85 & B5 & $5 A$ \\
\hline
\end{tabular}

\section{InvShiftRows}

\begin{tabular}{|c|c|c|c|}
\hline OD & $3 \mathrm{D}$ & 84 & 95 \\
\hline 32 & 20 & DA & D9 \\
\hline A6 & 26 & 73 & D3 \\
\hline 85 & B5 & $5 A$ & B9 \\
\hline
\end{tabular}

\section{InvSubBytes}

\begin{tabular}{|c|c|c|c|}
\hline F3 & $8 \mathrm{~B}$ & $4 \mathrm{~F}$ & $\mathrm{AD}$ \\
\hline $\mathrm{A} 1$ & 54 & $7 \mathrm{~A}$ & $\mathrm{E} 5$ \\
\hline $\mathrm{C} 5$ & 23 & $8 \mathrm{~F}$ & $\mathrm{~A} 9$ \\
\hline 67 & $\mathrm{D} 2$ & 46 & $\mathrm{DB}$ \\
\hline
\end{tabular}

....

$\underline{\text { Round } 10}$

Text

\begin{tabular}{|c|c|c|c|}
\hline A0 & $9 \mathrm{D}$ & F9 & C3 \\
\hline 54 & 90 & B6 & EA \\
\hline ED & 12 & $2 A$ & 89 \\
\hline 17 & 23 & E4 & 24 \\
\hline
\end{tabular}

InvMixColumns

\begin{tabular}{|c|c|c|c|}
\hline D2 & $1 \mathrm{~B}$ & $3 \mathrm{~B}$ & $\mathrm{FC}$ \\
\hline $2 \mathrm{C}$ & 39 & $6 \mathrm{~A}$ & $\mathrm{ED}$ \\
\hline 63 & $3 \mathrm{~B}$ & 83 & $\mathrm{D} 1$ \\
\hline $\mathrm{ED}$ & $4 \mathrm{~A}$ & $4 \mathrm{~A}$ & 50 \\
\hline
\end{tabular}

\section{RoundKey 1}

\begin{tabular}{|c|c|c|c|}
\hline E5 & 91 & F8 & 8D \\
\hline 96 & FE & 8D & EF \\
\hline F9 & 98 & B8 & D1 \\
\hline F4 & 98 & D4 & A7 \\
\hline
\end{tabular}

InvShiftRows

\begin{tabular}{|c|c|c|c|}
\hline D2 & $1 \mathrm{~B}$ & $3 \mathrm{~B}$ & $\mathrm{FC}$ \\
\hline 39 & $6 \mathrm{~A}$ & $\mathrm{ED}$ & $2 \mathrm{C}$ \\
\hline 83 & $\mathrm{D} 1$ & 63 & $3 \mathrm{~B}$ \\
\hline $4 \mathrm{~A}$ & $4 \mathrm{~A}$ & 50 & $\mathrm{ED}$ \\
\hline
\end{tabular}

AddRoundKey

\begin{tabular}{|c|c|c|c|}
\hline 45 & $0 \mathrm{C}$ & 01 & $4 \mathrm{E}$ \\
\hline $\mathrm{C} 2$ & $6 \mathrm{E}$ & $3 \mathrm{~B}$ & 05 \\
\hline 14 & $8 \mathrm{~A}$ & 92 & 58 \\
\hline $\mathrm{E} 3$ & $\mathrm{BB}$ & 30 & 83 \\
\hline
\end{tabular}

InvSubBytes

\begin{tabular}{|c|c|c|c|}
\hline $7 \mathrm{~F}$ & 44 & 49 & 55 \\
\hline $5 \mathrm{~B}$ & 58 & 53 & 42 \\
\hline 41 & 51 & 00 & 49 \\
\hline $5 \mathrm{C}$ & $5 \mathrm{C}$ & $6 \mathrm{C}$ & 53 \\
\hline
\end{tabular}

Kemudian melakukan 3 perhitungan terakhir, hasil dari InvSubBytes ronde ke-10 di-XOR-kan dengan cipherkey atau kunci ronde ke-0.

\begin{tabular}{|c|c|c|c|}
\hline $7 \mathrm{~F}$ & 44 & 49 & 55 \\
\hline $5 \mathrm{~B}$ & 58 & 53 & 42 \\
\hline 41 & 51 & 00 & 49 \\
\hline $5 \mathrm{C}$ & $5 \mathrm{C}$ & $6 \mathrm{C}$ & 53 \\
\hline
\end{tabular} \begin{tabular}{|l|l|l|l|}
\hline $4 \mathrm{E}$ & 74 & 69 & 75 \\
\hline $6 \mathrm{~F}$ & 68 & 73 & 62 \\
\hline 76 & 61 & 20 & 69 \\
\hline 69 & $6 \mathrm{C}$ & $4 \mathrm{C}$ & 73 \\
\hline
\end{tabular}$=$\begin{tabular}{|l|l|l|l|l|}
\hline 31 & 30 & 20 & 20 \\
\hline 34 & 30 & 20 & 20 \\
\hline 37 & 30 & 20 & 20 \\
\hline 35 & 30 & 20 & 20 \\
\hline
\end{tabular}

Selanjutnya adalah mengubah hasil dari InvSubBytes ronde ke-10 di-XOR-kan dengan cipherkey ke dalam bentuk bilangan desimal kemudian diubah lagi kedalam bentuk text berdasarkan kode ASCII.

PlainText

$$
\begin{array}{|l|l|l|l|l|l|l|l|l|l|l|l|l|l|l|l|}
\hline 31 & 34 & 37 & 35 & 30 & 30 & 30 & 30 & 20 & 20 & 20 & 20 & 20 & 20 & 20 & 20 \\
\hline
\end{array}
$$

\begin{tabular}{|l|l|l|l|l|l|l|l|l|l|l|l|l|l|l|l|}
\hline 1 & 4 & 7 & 5 & 0 & 0 & 0 & 0 & & & & & & & & \\
\hline
\end{tabular}

\section{IMPLEMENTASI DAN UJI COBA}

\subsection{Form Menu Utama}

Form Menu Utama merupakan form induk dari semua form yang ada pada sistem. Dimana terdapat 3 sub menu pada form Menu Utama yaitu File, Proses, Keluar. Berikut ini tampilan form Menu Utama:

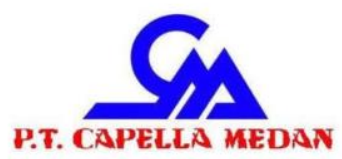

IMPLEMENTASI KEAMANAN DATA GAJI KARYAWAN

PADA PT. CAPELLA MEDAN MENGGUNAKAN

METODE ADVANCED ENCRYPTION STANDARD (AES)

Gambar 10 Tampilan Form Menu Utama 
1. Form Data Karyawan

Form data karyawan digunakan untuk meng-input data karyawan.

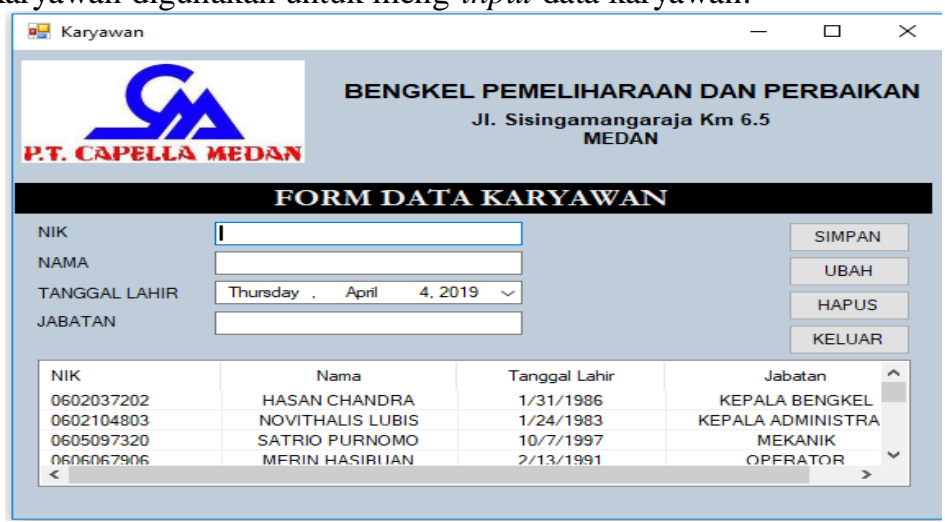

Gambar 11 Tampilan Form Data Karyawan

2. Form Data Gaji Karyawan

Form data gaji karyawan digunakan untuk meng-input-kan data gaji seluruh karyawan.

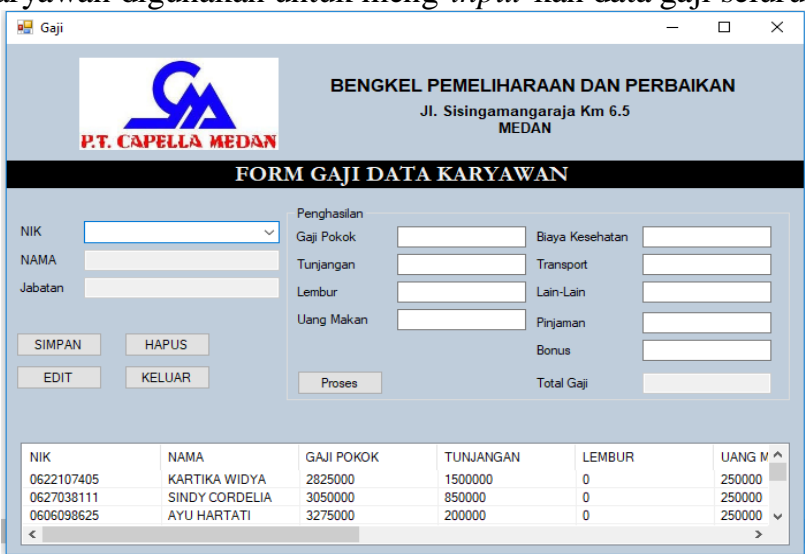

Gambar 12 Tampilan Form Data Gaji karyawan

3. Form Enkripsi Data

Form enkripsi berisikan tentang file yang diproses ke algoritma AES dan komponen dalam program yang berbasis desktop.

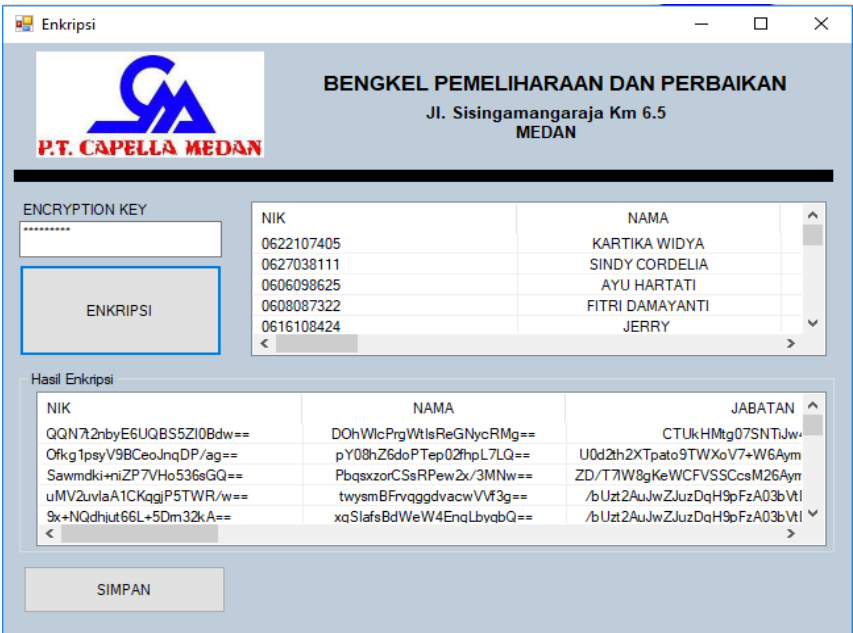

Gambar 13 Tampilan Form Enkripsi Data

4. Form Dekripsi Data dibaca.

Form dekripsi digunakan untuk mengembalikan data yang sebelumnya sudah dienkripsi agar dapat 


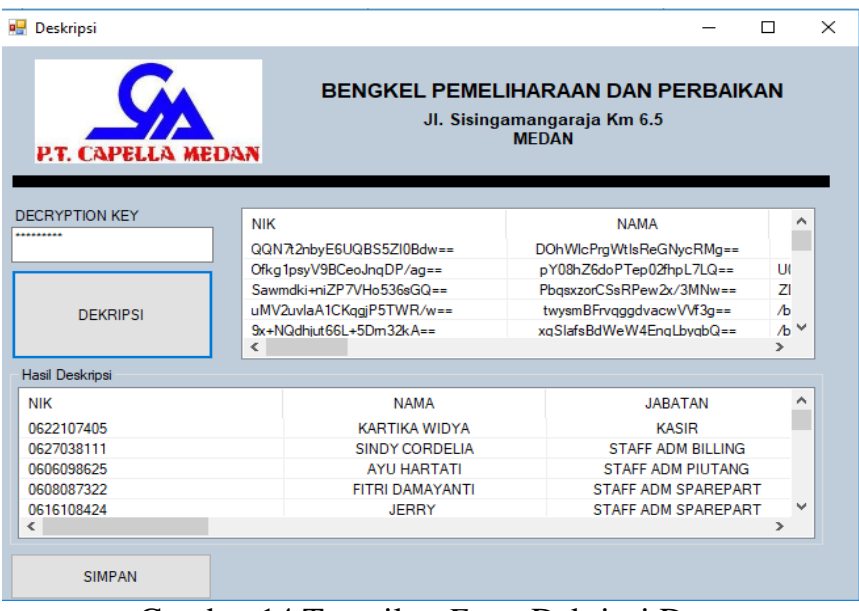

\section{KESIMPULAN}

Gambar 14 Tampilan Form Dekripsi Data

Kesimpulan yang dapat diambil dalam pembuatan sistem keamanan data gaji pada PT. Capella Medan dengan menggunakan metode Advanced Encryption Standard (AES) antara lain:

1. Perancangan sistem keamanan data gaji dapat dilakukan dengan menggunakan bahasa pemrograman berbasis desktop guna mempermudah proses mengamankan data gaji pada PT. Capella Medan.

2. Dalam mengamankan data gaji, metode Advanced Encryption Standard bekerja dengan sangat baik, data gaji mengalami beberapa tahap proses transformasi sehingga akhirnya menjadi teks yang tersandikan.

3. Penerapan metode Advanced Encryption Standard dalam mengamankan data gaji dapat mempermudah perusahaan dalam menjaga kerahasiaan data gaji karyawan dari orang yang tidak memiliki wewenang terhadap data tersebut.

\section{DAFTAR PUSTAKA}

[1] Candra, B., Wahyudi, J., \& Hermawansyah. (2014). Pengembangan Sistem Keamanan Untuk Toko Online Pemrograman Php Dan Mysql. Jurnal Media Infotama, 11(1), 31-39.

[2] Dony Ariyus. (2018). Kriptografi Keamanan Data dan Komunikasi (Pertama Ce). Yogyakarta: GRAHA ILMU.

[3] Dr.Suarga,M.Sc.,M.Math., P. . (2012). Algoritma dan Pemrograman. (ANDI OFFSET, Ed.). Yogyakarta.

[4] Hanafi, J. I., \& Patombongi, A. (2016). Aplikasi Sms Kriptografi Menggunakan Metode Aes Berbasis Android, 1(1), 69-75.

[5] Hendrayudi. (2011). Dasar Dasar Pemrograman Microsoft Visual Basic 2008. Bandung: CV YRAMA WIDYA.

[6] Informasi, S., Pada, P., Menengah, S., Pacitan, M., \& Utami, R. (2014). Sistem Informasi Penggajian Pada Sekolah Menengah Atas ( SMA ) Muhammadiyah Pacitan Reny Utami, 6(3), 32-35.

[7] Jiwandono, A., Bandung, I. T., \& Bandung, J. G. (2011). Implementasi AES-ECB 128-bit untuk Komputasi Paralel pada GPU menggunakan Framework NVIDIA CUDA, 1-5.

[8] Keamanan, A. S. (2014). Pengembangan Sistem Keamanan Untuk Toko Online Pemrograman Php Dan Mysql, 11(1).

[9] Lestari, D. (2014). Perancangan Sistem Informasi Penggajian Karyawan Pada PR. Tunas Mandiri Kabupaten Pacitan. Perancangan Sistem Informasi Penggajian Karyawan Pada PR. Tunas Mandiri Kabupaten Pacitan, 3(4), 22-26.

[10] Mardiana, A. (2017). Jurnal Economix Volume 1 Nomor 1 Juni 2013, 1(X), 11-22. https://doi.org/10.1016/j.neuroimage.2007.11.048

[11] Rifki Sadikin. (2012). Kriptografi Untuk Keamanan Jaringn. Yogyakarta: ANDI OFFSET. 
[12] Rosa A.S M. Salahudin. (2013). Rekayasa Perangkat Lunak. (Informatika, Ed.). Bandung.

[13] Tulloh, A. R., Permanasari, Y., \& Harahap, E. (2016). Kriptografi Advanced Encryption Standard ( AES ) Untuk Penyandian File Dokumen. Jurnal Matematika UNISBA, 2(1), 118-125.

[14] Warkim, Lewenusa, I., \& Karo, P. K. (2016). Kriptografi Algoritma Advanced Encryption Standard Dan Pengecekan Error Detection Cyclic Redundancy Check, (April). 